\title{
A high resolution reference data set of German wind velocity 1951-2001 and comparison with regional climate model results
}

\author{
Andreas Walter ${ }^{* 1,2}$, Klaus Keuler ${ }^{2}$, DAniela JaCoB ${ }^{3}$, Richard KNOCHE ${ }^{4}$, Alexander \\ Block $^{2}$, SVEn Kotlarski ${ }^{3}$, Gerhard MÜller-Westermeier ${ }^{1}$, Diana ReCHid ${ }^{3}$ and \\ WILFRIED AHRENS ${ }^{2}$
}

${ }^{1}$ Deutscher Wetterdienst, Offenbach a.M., Germany

${ }^{2}$ Brandenburgische Technische Universität, Cottbus, Germany

${ }^{3}$ Max-Planck Institut für Meteorologie, Hamburg, Germany

${ }^{4}$ Institut für Meteorologie und Klimaforschung, Forschungszentrum Karlsruhe, Garmisch-Partenkirchen, Germany

(Manuscript received February 1, 2006; in revised form May 5, 2006; accepted June 26, 2006)

\begin{abstract}
A high resolution $(1 \mathrm{~km} \times 1 \mathrm{~km})$ data set of monthly wind velocities over Germany for the time period 19512001 is provided. The data have been reduced to a reference level using a so called 'relative altitude' scheme, interpolated using a simple Inverse Distance Weighting approach and retransformed to the actual topography. However, no parametrization of land use or surface roughness has been integrated in the modelling process of this data and therefore the data is not suitable to serve as criteria for planning wind energy sites. A CrossValidation scheme applied to this data set yields a mean error of $0.1 \mathrm{~m} / \mathrm{s}$ for the time period 1951-2001. Regarding the area mean of wind velocities a linear trend of $-0.05 \mathrm{~m} / \mathrm{s}$ is obvious for this period. This negative linear trend changes to a positive one when shorter time scales are considered, e.g. $+0.3 \mathrm{~m} / \mathrm{s}$ for the 1981-2001 period. However, all these temporal trends are not significant. Thus, they could be the result of random features within the dataset and are not further interpreted. These monthly derived wind velocities serve as a reference data set for regional climate model evaluations. The climate models used are two different versions of the hydrostatic regional climate model REMO as well as the nonhydrostatic CLM and MM5 models. All models are capable to reproduce the temporal and spatial variability of the observations to a great extent. Projections of changes in wind velocity have been carried out with these regional climate models. All of these projections show a significant increase in wind velocities over the full model domain, especially over the Baltic Sea and the North Sea, during winter and a decrease during summer. Regarding changes in annual means an increase of up to $1.0 \mathrm{~m} / \mathrm{s}$ for the Baltic Sea and a decrease in wind velocitites of the same magnitude for the Mediterranean is projected as an average for the 2070-2099 period.
\end{abstract}

\begin{abstract}
Zusammenfassung
Ein hochaufgelöster Datensatz $(1 \mathrm{~km} \times 1 \mathrm{~km})$ monatlicher Windgeschwindigkeiten für Deutschland im Zeitraum 1951-2001 wurde erstellt. Die Daten wurden mit Hilfe einer sog. 'relativen Stationshöhe' auf ein einheitliches Bezugsniveau reduziert, hier mit einem Inverse Distance Verfahren interpoliert und anschliessend wieder auf die reale Topographie retransformiert. Da zum Zweck der Evaluierung von regionalen Klimamodellen keine Parametrisierung der Landnutzung bzw. der Rauhigkeit in den Modellierungprozess eingeht, sind die erhaltenen Daten zur Planung potentieller Standorte von Windenergieanlagen jedoch nicht geeignet. Eine Abschätzung des durch das Interpolationsverfahren bedingten Fehlers mittels Cross-Validation ergab einen mittleren Fehler von 0,1 m/s im Zeitraum 1951-2001. Für diesen Zeitraum liegt der lineare Trend der mittleren Windgeschwindigkeit für Deutschland bei $-0,05 \mathrm{~m} / \mathrm{s}$. Auf kürzeren Zeitskalen kehrt sich dieser Trend um, z.B. $+0,3 \mathrm{~m} / \mathrm{s}$ im Zeitraum 1981-2001. Jedoch sind alle gefundenen Trends nicht signifikant. Diese zeitlichen Trends können somit zufällig sein und werden nicht weiter interpretiert. Die erhaltenen hochaufgelösten Felder mittlerer Windgeschwindigkeit dienen weiterhin als Referenzdatensatz zur Evaluierung regionaler Klimamodelle. Die hierzu verwendeten Modelle sind zwei Versionen des hydrostatischen regionalen Klimamodells REMO sowie die nichthydrostatischen Modelle CLM und MM5. Es zeigt sich, dass alle Modelle die Beobachtungsdaten sowohl in ihrer zeitlichen als auch räumlichen Struktur gut reproduzieren. In einem letzten Schritt wurden die regionalen Klimamodelle im Scenario-Mode betrieben. Alle hierzu verwendeten Klimamodelle zeigen eine deutliche Erhöhung der Windgeschwindigkediten über dem gesamten Modellgebiet, vor allem über der Ost- und Nordsee, für die Wintermonate und eine Abnahme der Windgeschwindigkeiten in den Sommermonaten. Werden jährliche Mittelwerte dieser Scenarienrechnungen betrachtet, so zeigen sich im Mittel für den Zeitraum 2070-2099 eine Zunahme der Windgeschwindigkeiten um bis zu $1 \mathrm{~m} / \mathrm{s}$ im Ostseegebiet und eine Abnahme um den selben Betrag im Mittelmeerraum.
\end{abstract}

*Corresponding author: Andreas Walter, Institute for Atmospheric Physics, Johannes Gutenberg-University Mainz, 55099 Mainz, Germany, e-mail: WalterA@uni-mainz.de 


\section{Introduction}

Projections of climate change are inevitably uncertain. The assessment of climate change impacts is typically faced with a wide range of predicted changes from different scenarios calculated by different models of unknown relative quality, influenced by unquantified uncertainties in the modelling process itself. Thus, the quantification of uncertainties in climate change simulations is urgently requested and a major point of scientific interest (ALLEN et al., 2000); (FOREST et al., 2002); (MURPHY et al., 2004).

One of the most important issues in an anthropogenically changed climate is the question, whether wind velocities will be modified significantly too. This would not only affect possible insurance budgets due to damaging wind storms, but also the efficiency of wind power as a potential natural energy source (BENESCH et al., 1978).

Unlike other recent studies, e.g. (WEISSE et al., 2005), we will focus on monthly data, thus giving up the possibility of extreme value statistics. The monthly mean values analysed herein provide an assured data basis for the evaluation of regional climate models and if compared to regional climate models simulations reflect the ability of these models to reproduce the mean state of the climate system concerning wind velocity. Thus, the ability of these modesl to project future changes in mean wind velocity can be analyzed most efficiently.

The analysis in this study concentrates on the wind velocity over Germany for the period 19512001, which is a major focal point in the DEKLIM (German Climate Research Program, www.deklim.de) project QUIRCS (Quantification of Uncertainties In Regional Climate and climate change Simulations, www.tu-cottbus.de/meteo/Quircs/home.html). The aim of QUIRCS is to quantify uncertainties in regional climate simulations by comparing results of high resolution regional climate models to various observational data sets.

High resolution $(1 \mathrm{~km} \times 1 \mathrm{~km})$ data sets of numerous climatological variables have been compiled by the German Meteorological Service (DWD) to obtain a reliable data base for these evaluation issues. The data sets are based on all available measurements by official DWD stations throughout Germany.

Because of the dependency of wind on its surroundings interpolation in space reveals major difficulties if stations which might have the same height above sea level and are belonging to different wind regimes, e.g. coastal or alpine, are used. Therefore, an alternative methodology will be presented, which allows to generate area averaged wind velocities: a feasible wind velocity-altitude dependency is obtained using a so called 'relative altitude'. This dependency is used to reduce the height dependancy of wind velocity to a reference level. The reduced wind velocity is then interpolated onto a $1 \mathrm{~km} \times 1 \mathrm{~km}$ grid by an Inverse Distance Weighting (IDW) algorithm and finally retransformed to real topography using the same height dependancy. This gridded data base can be used for further interpolation to coarser grids like those used in regional climate modelling. On these grids the actual model evaluation is performed. The data and methodology will be described in section 2. A brief description of the climate models used in this study is given in section 3 and, finally, outcomings of the evaluation and projection of future changes in wind velocity using these regional climate models are presented in section 4 .

\section{Data and methodology}

To obtain a data base as dense as possible for such a high-frequent variable as wind velocity we used three wind velocity measurements per day taken at climatological standard times ( 7 a.m., 2 p.m. and 9 p.m.). These measurements were taken at every available climate station of the German Meteorological Service (DWD) throughout Germany and their daily mean served as an estimation of daily mean wind velocity. Thus, the number of stations available varies monthly with a minimum of 73 stations and a maximum of 113 stations. Especially in the early times of our investigation period 1951-2001 there are only occasional direct wind measurements available, thus this data base for the interpolation at these early times seems rather insecure with only a coarse spatial resolution. We therefore abandoned the claim of 'exact' data measurements, instead obtaining a data base as dense as possible and go back in time as long as possible. Both direct measurements as well as estimated wind velocities only exist for a couple of stations back to 1951. At the station 'Brocken', the windiest place in Germany (SCHULZE, 1993), a correlation of 0.9 between these two representations of the same climatological variable is obtained. Further temporal averaging of both measurements tends to smooth the data, so that we conclude that estimated wind velocities represent the real atmospheric conditions to a great extent.

The obtained daily means are furthermore averaged in time to obtain an estimation of monthly means at each location. Each station altitude $\left(h_{\text {station }}\right)$ is then transformed to a so called 'relative altitude' using the following scheme: The station is centered in an area $\Gamma$ of $10 \mathrm{~km} \times 10 \mathrm{~km}$, which is equivalent to 100 grid points of the projection grid. After testing various sizes $\Gamma=(10$ $\mathrm{km})^{2}$ has been chosen as a suitable representation of the wind velocity-altitude dependency. In this way the wind velocity-altitude dependency can be linearized most efficiently, see Fig. 1. 


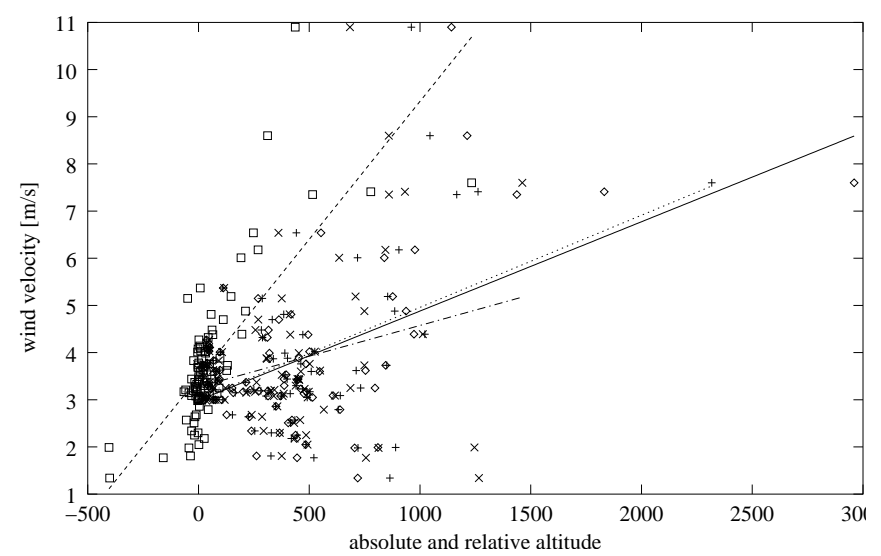

Figure 1: Wind speed as a function of altitude and relative altitude for 2001 (annual mean). Shown are different representations of the wind velocity-altitude dependency corresponding to different sizes of the area $\Gamma$ in Eq. $1 . \diamond$ marks real altitude, + corresponds to relative altitude with a surrounding area of $5 \mathrm{~km} \times 5 \mathrm{~km}$, the boxes correspond to an area of $10 \mathrm{~km} \times 10 \mathrm{~km}$ and $\times$ corresponds to $20 \mathrm{~km}$ $\times 20 \mathrm{~km}$. The solid line is the linear regression for real station altitude $\left(r^{2}=0.31\right)$, the dotted line is the regression for relative altitude $\Gamma=(5 \mathrm{~km})^{2}\left(r^{2}=0.23\right)$, the dashed line is the regression for $\Gamma=$ $(10 \mathrm{~km})^{2}\left(r^{2}=0.56\right)$ and the dashed-dotted line is the regression for $\Gamma=(20 \mathrm{~km})^{2}\left(r^{2}=0.07\right)$.

In the next step the mean altitude $\bar{h}_{\Gamma}$ within $\Gamma$ is determined. The relative station altitude $h_{r e l}$ is then computed by

$$
h_{\text {rel }}=h_{\text {station }}-\bar{h}_{\Gamma} \text {. }
$$

The transformation to this 'relative station altitude' provides a suitable description of the topography of the area surrounding each station, in particular the exposition of the station, i.e. hillside or valley-side location. For example the DWD station Garmisch-Partenkirchen, located in a subalpine valley, has an altitude of $710 \mathrm{~m}$ above sea level. Germany's highest peak, the Zugspitze, just a few kilometers away from Garmisch-Partenkirchen, has an altitude of $2960 \mathrm{~m}$ above sea level. It is obvious that, because of their exposure, wind regimes at these two locations are quite different. In addition, the highest peak in northern Germany, the Brocken (1142 m above sea level), has a similar altitude as Garmisch-Partenkirchen, but as mentioned above the Brocken is the windiest place in Germany, which is due to the fact that approaching flows are relatively unhindered because of the flat and smooth topography of Northern Germany's lowlands. Thus, a simple linear regression to calculate altitude - wind velocity dependencies would reveal too generalized results, which would not reflect the local characteristics of the measuring sites.

The relative altitude of a site reflects its specific exposure better than its actual topographic altitude, e.g. $h_{\text {rel }}$ Garmisch-Partenkirchen -401 m, $h_{\text {rel }}$ Zugspitze $1233 \mathrm{~m}$ and $h_{\text {rel }}$ Brocken $427 \mathrm{~m}$. By using this rela-

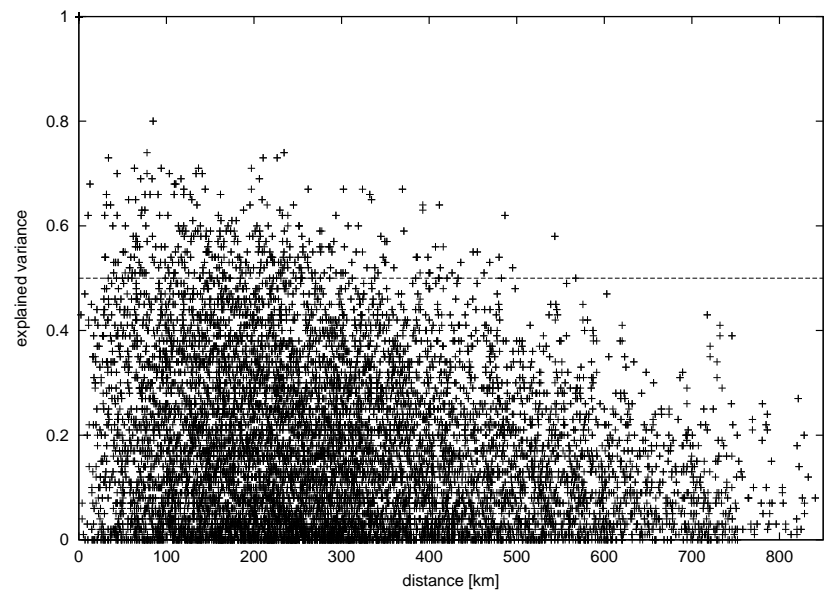

Figure 2: Explained variance between time series of wind data as a function of distance between measuring stations, i.e. spatial decorrelation. The solid line indicates the $50 \%$ explained variance level.

tive altitude scheme the dependency between station altitude/location and wind velocity can be objectively linearized, which implies a more suitable representation of the data for further purposes, see again Fig.1 for further details.

The obtained wind-altitude dependency is used to reduce observed wind velocities to a reference level where all values can be horizontally interpolated onto a $1 \mathrm{~km} \times$ $1 \mathrm{~km}$ grid using a standard Inverse Distance Weighting (IDW) routine

$$
\mathscr{Z}\left(s_{0}\right)=\sum_{i=1}^{N} \lambda_{i} Z\left(s_{i}\right),
$$

where $\lambda_{i}$ are the weights of each observational value at point $i . Z\left(s_{i}\right)$ is the observed value at location $s_{i}$ and $N$ is the total number of observations contributing to the gridbox value at location $s_{0}$. The $\lambda_{i}$ can be determined by

$$
\lambda_{i}=\frac{d_{i 0}^{-p}}{\sum_{i=1}^{N} d_{i 0}^{-p}},
$$

where $d_{i 0}$ is the distance between the point of observation $\left(s_{i}\right)$ and the point onto which these observations are projected $\left(s_{0}\right)$. In this way approximations $\left(\mathscr{Z}\left(s_{0}\right)\right)$ for all grid points can be obtained. In Eq. (2.3) we have chosen $p=2$, i.e. Inverse Distance Squared Weighting (HARTKAMP et al., 1999); (DITTMANN et al., 1999). In a final step these interpolated values are retransformated to real topographic altitude using the previously determined linear height dependancy, thus obtaining a $1 \mathrm{~km}$ $\times 1 \mathrm{~km}$ gridded data field.

The interpolation of the surface wind field onto a rectangular grid using IDW has been applied in numerous studies (GOODIN et al., 1979; SHERMAN, 1978; Ross et al., 1988; MATHuR and Peters, 1990). IDW is a deterministic estimation method in which values at unsampled points are determined by a linear combination of 
values at known sampled points. Weighting of nearby points is strictly a function of distance and no other criteria are considered. The underlying assumption is, that values closer to unsampled locations are more representative of the value to be estimated than values from samples further away, which is certainly true for wind velocity because wind measurements, in contrast to temperature, have a very limited spatial representativeness. The mutually explained variance between wind measurements decreases rapidly with distance, e.g. from a distance of $200 \mathrm{~km}$ onward most stations have a mutual explained variance of less than $50 \%$ (Fig. 2). Following this result, we chose a maximum interpolation radius of $R=200 \mathrm{~km}$, i.e. stations farther apart than $200 \mathrm{~km}$ were not considered for interpolation $\left(d_{i 0} \leq 200 \mathrm{~km}\right.$ in Eq. (2.3). (Goodin et al., 1979) give a formula to compute the optimum of this radius of influence which is based on the average station separation $d$. For a two dimensional area $A$ with $N$ randomly distributed stations, the average station density $\rho$ and station separation $d$ are given by $\rho=N / A$ and $d=(A / N)^{\frac{1}{2}}$. (STEPHANS and STITT, 1970) have shown empirically that the optimum search radius $R$ for large signal-to-noise ratios is $R / d \approx 1.6$. With $N$ ranging from 73 to 113 in this study we obtain an optimum radius from $\approx 110 \mathrm{~km}$ to $\approx 90 \mathrm{~km}$ respectively. (STEPHANS and STITT, 1970) recommend that $R$ should be overestimated rather than underestimated, so our choice of a maximum interpolation radius of $200 \mathrm{~km}$ seems to be in good accordance with their findings.

Thus, it is plausible that nearby observations obtain a larger weight than observations from further away. The spatial orientation of the sample points does not affect the weighting.

\subsection{Cross validation}

To get some kind of information about the quality of the obtained interpolated data set a Cross-Validation (STONE, 1974); (MiCHAELSEN, 1987) was performed. For each of the 612 months investigated every single station measurement has been gradually taken out of the data base thus performing the interpolation $N$ times with $N-1$ stations each month. In this manner an error between interpolated value and measured value at every omitted station can be computed. We obtained a spatial and temporal averaged mean error of $0.1 \mathrm{~m} / \mathrm{s}$ during the period 1951 to 2001 . The maximum mean error has been computed to $0.3 \mathrm{~m} / \mathrm{s}$ and the maximum absolute error was $12.8 \mathrm{~m} / \mathrm{s}$ at the station 'Brocken' in January 1998. In $71 \%$ out of the 612 cases considered (51 years), the maximum error was obtained at the station 'Brocken', which is due to the immense variability at this location and reflects the specific topographical conditions at this location. These errors have to be taken into account when interpreting the outcomings of the regional climate models for the validation period 1979-1993.

\section{Regional climate models used in this study}

The climate models used in this study are two different versions (5.0 and 5.1) of the hydrostatic regional climate model REMO and the nonhydrostatic models CLM and MM5, brief descriptions of these models follow.

\subsection{REMO}

REMO is based on the Europamodell, the former numerical weather prediction model of the DWD (MAJEWSKI, 1991). The model was further developed at the Max Planck Institute for Meteorology, where the dynamical core has slightly been changed and additional physical parameterizations from the Global Circulation Model (GCM) ECHAM4 (ROECKNER et al., 1996) have been implemented (JACOB and PODZUN, 1997; JACOB, 2001). Additionally, in the REMO 5.1 version mean annual cycles of vegetation characteristics, freezing and melting of soil water and fractional land use have been integrated. Another difference between these two simulations with REMO is that the REMO 5.1 run covers a larger area than that of version 5.0. The REMO 5.0 model domain is approximately Central Europe, whereas the REMO 5.1 model domain includes large parts of the North Atlantic, as far north as Greenland, and parts of Northern Africa as well. This means that REMO 5.1 has more degrees of freedom. The interior model area is less coupled to the prescribed boundary values, thus the lateral forcing can only be detected in the outermost eight boxes.

Though both regional climate model versions cover Central Europe, we will focus on Germany for their comparison with observations in this study. The spatial resolution of the models is roughly $18 \mathrm{~km}$ and both REMO versions use 20 vertical levels. The simulations of the 15 year evaluation period 1979-1993 are laterally forced with re-analysis data provided by ECMWF for this period (ERA 15) (ECMWF Reports, 1997-1999).

\subsection{CLM}

The CLM (Climate Limited Area Model) is the climate version of DWD's operational Lokal Modell (DoMS and SCHAETTLER, 1999) and is based on the primitive hydro-thermodynamical equations describing compressible non-hydrostatic flow in a moist atmosphere without any scale approximations. The horizontal and vertical wind components are prognostic variables of the CLM. The CLM's model domain is approximately Europe and its spatial resolution and grid structure identical to REMO'S, i.e. $1 / 6^{\circ}(\approx 18 \mathrm{~km} \times 18 \mathrm{~km})$ and the large scale forcing again comes from ECMWF reanalysis data. No projections of future winds with the CLM have been carried out for this study, thus the CLM only serves as a reference during the evaluation period. 


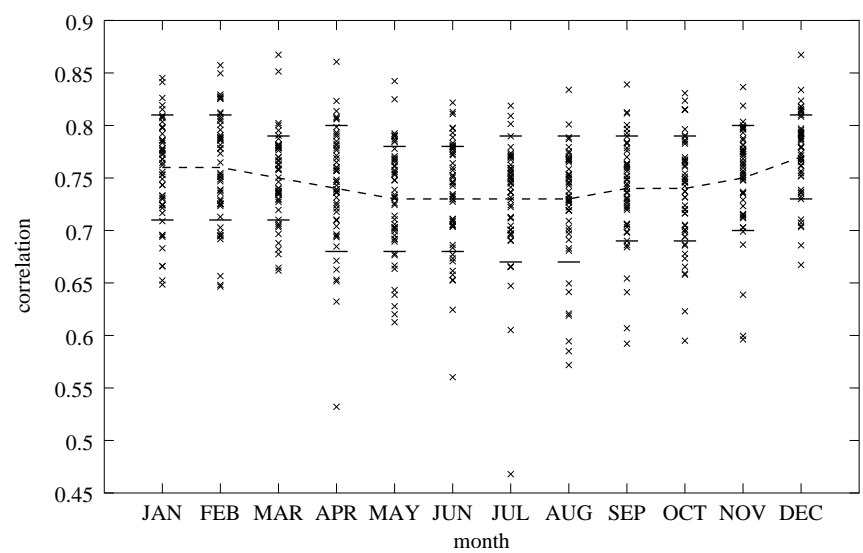

Figure 3: Variability of the spatial correlation coefficient modeledobserved for the period 1951-2001. The $\times$ indicates the 51 correlation coefficients obtained per month, the dashed line is the mean correlation coefficient for each month, whereas the horizontal bars indicate the $\pm 1 \sigma$ interval for these monthly correlation coefficients.

\subsection{MCCM/MM5}

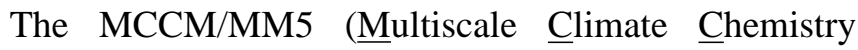
Model) is based on the Penn State/NCAR nonhydrostatic mesoscale model MM5 (DUDHIA, 1993). The MM5 is a limited-area, nonhydrostatic, terrain-followingsigma-coordinates model designed to model or predict mesoscale and regional scale atmospheric circulation and is described in detail in (GRELL et al., 1993). Previous applications of the MM5 focused on climate modeling over complex terrain (GRELL et al., 2000a, b), thus the MM5 was choosen as the model of choice for the complex terrain in southern Germany in the BAYFORKLIM (www.bayforklim.uni-muenchen.de) and the BayForUV projects (FORKEL and KNOCHE, accepted).

Before performing the comparison between all data sets, modelled and observed, all data sets were projected on a $1 / 6^{\circ}$ reference grid using an area weighting interpolation method.

\section{Results, interpretation and outlook}

After reducing the wind velocity-altitude dependency using the findings presented in section 2, an IDW interpolation with $p=2$ in Eq. 2(.3). (Inverse Distance Squared) was performed. Though this implies a fixed spatial dependency between station data, this method reveals robust results (mean correlation of observed versus modelled data $=0.74$ for the evaluation period). In Fig. 3 the variability of these correlation coefficients for each month during the 1951-2001 period is shown. An annual cycle of these coefficients becomes slightly visible with a maximum correlation in winter (strong winds) and a somewhat lower correlation during the period May to August. Though the coefficients do not differ very much $(0.73$ to 0.77$)$ this finding corresponds to

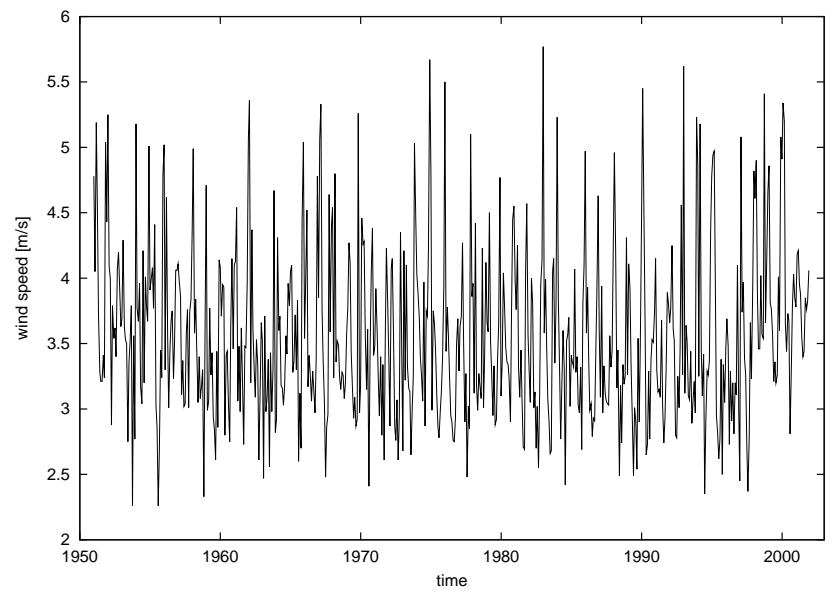

Figure 4: Monthly area mean wind velocity $[\mathrm{m} / \mathrm{s}]$ for Germany during the 1951-2001 time period.

the statement, that the accuracy of measurements tends to decrease with decreasing magnitude and thus during summer the regression does not reveal a statistical relationship as good as during periods of relatively strong winds.

Fig. 4 shows the area averaged monthly mean wind velocity for Germany in the period 1951-2001. Though only a small (negative) linear trend is detectable for this period $(-0.05 \mathrm{~m} / \mathrm{s})$, this trend intensifies on shorter time scales, i.e. $+0.11 \mathrm{~m} / \mathrm{s}$ for $1961-2001,+0.25 \mathrm{~m} / \mathrm{s} 1971-$ $2001,+0.39 \mathrm{~m} / \mathrm{s} 1981-2001$ and $+0.55 \mathrm{~m} / \mathrm{s} 1991-2001$. Since all trends are not significant they could be the result of random features within the dataset and will not be further interpreted. The maximum mean wind speed is modeled for January 1983 (area mean of 5.77 $\mathrm{m} / \mathrm{s}$ ), whereas minima occur in October 1953 and August 1955 (area mean of $2.26 \mathrm{~m} / \mathrm{s}$ ).

In Fig. 5 the mean wind field derived by DWD for the period 1951-2001 is plotted on its actual high resolution grid of $1 \mathrm{~km} \times 1 \mathrm{~km}$. The highest mean wind speed for this period is derived at the Brocken, see section 2, with an average of $>6.0 \mathrm{~m} / \mathrm{s}$, though the observed average at this location is $\approx 11 \mathrm{~m} / \mathrm{s}$. Other, spatially more representative maxima beside the isolated Harz region lie in the coastal region of northern Germany, Saxony's Erzgebirge (South-East) and the southern part of the Black Forest (South-West). In large parts of southern Germany only weak winds $(<3.0 \mathrm{~m} / \mathrm{s})$, with an absolute minimum in the Oberstdorf alpine valley, are derived. This distribution reflects the observed wind regime quite well and the monthly means serve further on as reference data for model evaluation for Germany.

In Fig. 6 the temporally averaged wind fields for the 1979-1993 evaluation period of observed data (top) as well as model outputs (lower two rows) are shown. Here the observed data has been interpolated onto the actual spatial resolution of the regional climate models, where 

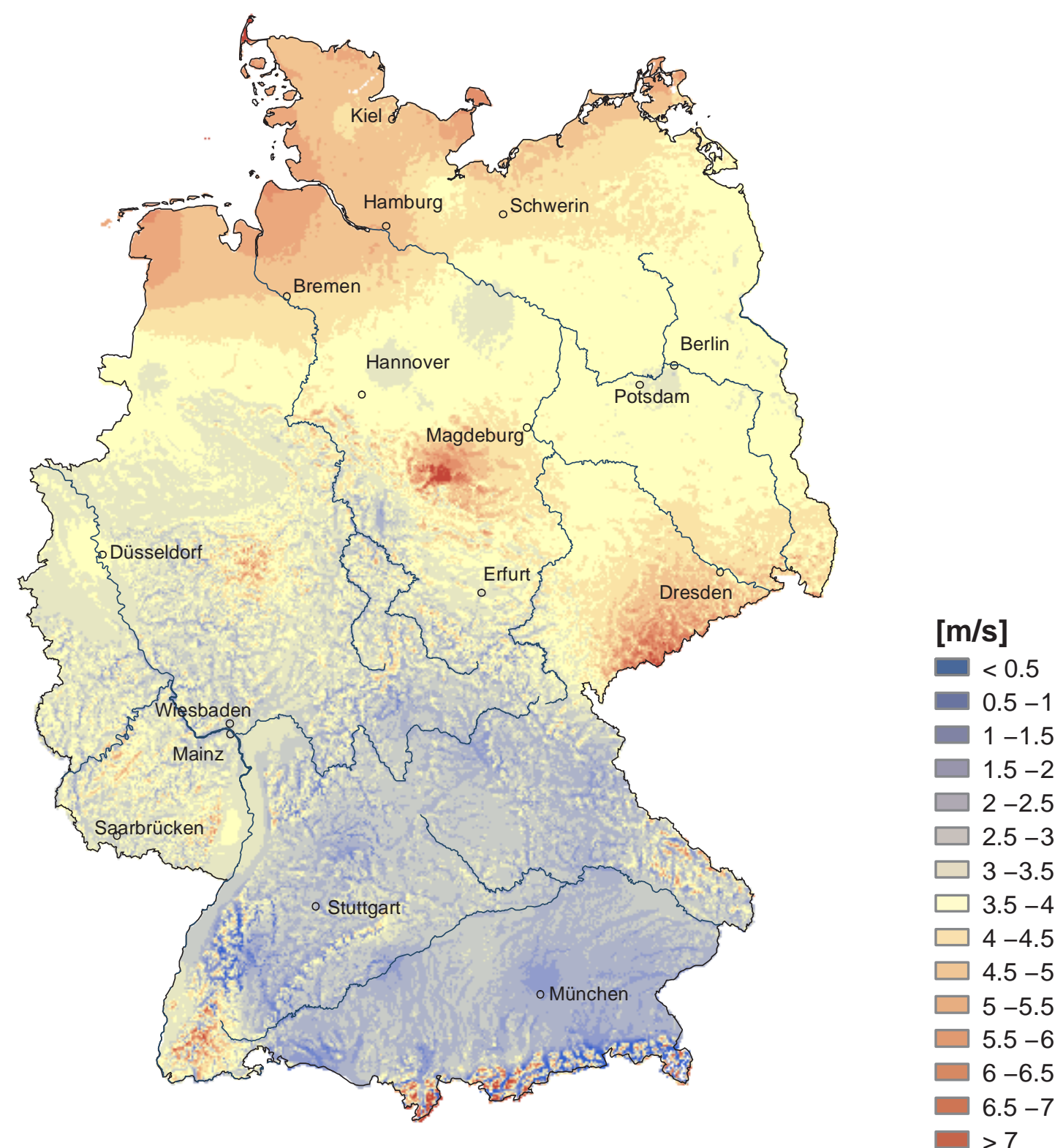

Figure 5: Temporally averaged high resolution grid $(1 \mathrm{~km} \times 1 \mathrm{~km})$ of annual mean wind velocity field for the evaluation period $1979-1993$ derived by DWD.

evaluation is performed. The derived wind field from observed data (top) relies on land based stations within Germany only. Thus, no values are available outside of Germany and for open water. The spatial distribution of this data is almost identical to the wind field already presented in Fig. 5 for the 1951-2001 period (spatial correlation of 0.88 ). Both REMO versions (top row) show a nearly identical spatial distribution, whereas the CLM (bottom row, right) shows less pronounced magnitudes, especially in the alpine region of southern Germany. Large areas inbetween coastal and alpine regions show slightly lower wind speeds and the wind velocity over open water is lower than in the two REMO versions. The outcomings of the MM5 (bottom row, left) reveal a smoother, unstructured spatial distribution, but show magnitudes in the alpine region comparable to those of both REMO versions. Again, wind speed over open water is reduced compared to the REMO findings. Regarding the bias of model to observations we find, that all models overestimate the mean conditions for the evaluation period, REMO $5.0+0.32 \mathrm{~m} / \mathrm{s}$, REMO $5.1+0.39$ $\mathrm{m} / \mathrm{s}, \mathrm{CLM}+0.19 \mathrm{~m} / \mathrm{s}$ and MM $5+0.48 \mathrm{~m} / \mathrm{s}$. The pattern correlation of the anomalies

$$
P A C O=\frac{1}{N-1} \sum_{i=1}^{N} \frac{\left(\operatorname{Mod}_{i}-\overline{M o d}\right)\left(O b s_{i}-\overline{O b s}\right)}{\sigma_{M o d} \sigma_{O b s}}
$$

amounts to 0.71 (both REMO versions), 0.79 (CLM) and 0.67 (MM5). In Eq. $4.1 N$ is the total number of grid points contributing and $\sigma_{M o d}, \sigma_{O b s}$ respectively are 

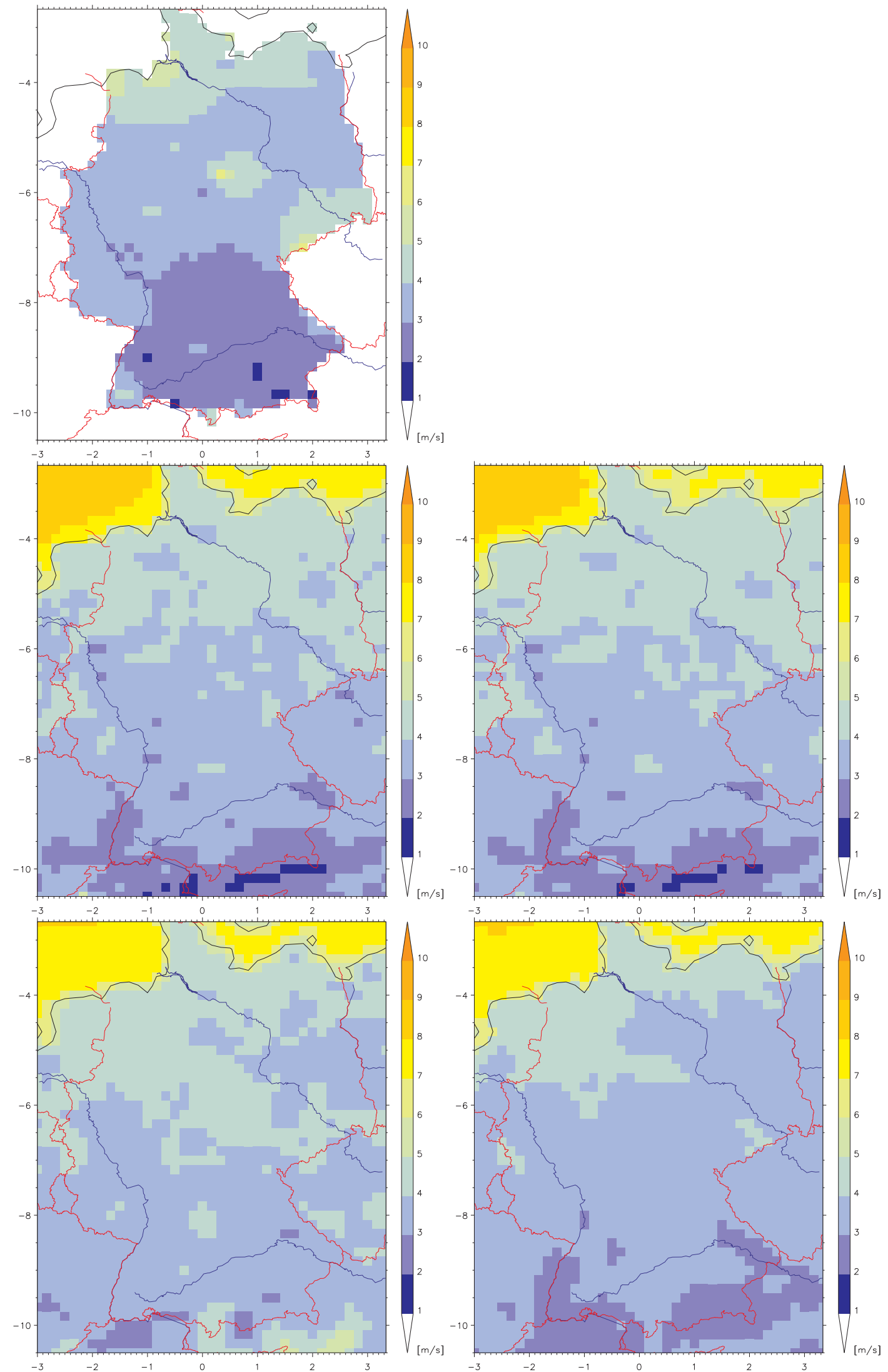

Figure 6: Outcomings for the evaluation period 1979-1993 in m/s. Observed data (top) and model output. Middle row: REMO 5.0 (left), REMO 5.1 (right), bottom row: MM5 (left) and CLM (right). For a brief description of the regional climate models see section 3. Results are shown on the actual $1 / 6^{\circ}$ model resolution. 

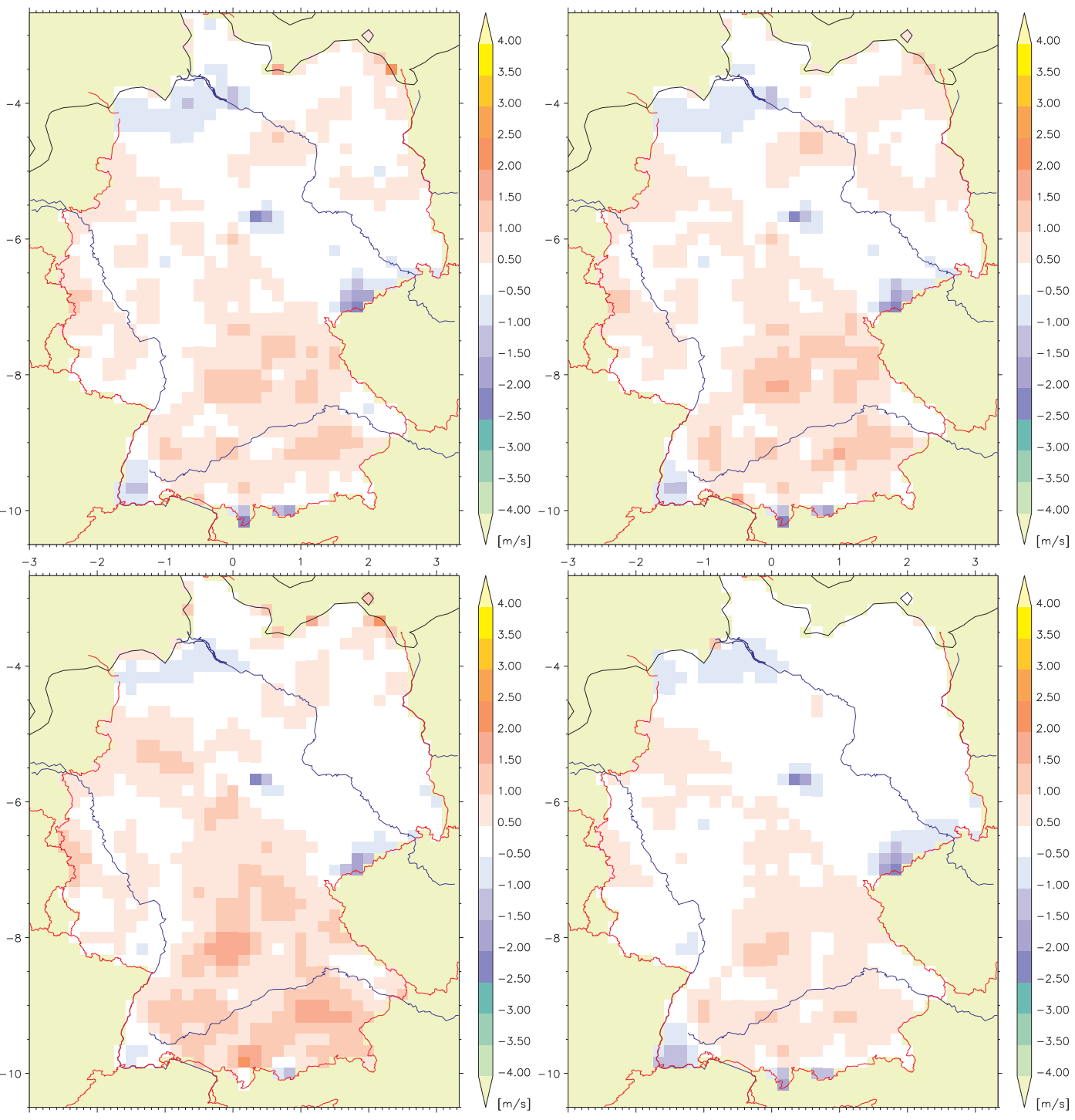

Figure 7: Spatial differences between modelled and observed wind velocity for the evaluation period 1979-1993. Top row: REMO 5.0 (left), REMO 5.1 (right), bottom row: MM5 (left) and CLM (right). These differences have been calculated on a $1 / 6^{\circ}$ reference grid, see section 2.1, which corresponds to the actual model grid.

the spatial standard deviations of modeled and observed data points. The bias can thus be defined as

$$
B I A S=\frac{1}{N} \sum_{i=1}^{N} \operatorname{Mod}_{i}-O b s_{i}=\overline{M o d}-\overline{O b s} .
$$

The spatial differences of modeled versus observed wind velocities for 1979 to 1993 are shown in Fig. 7. Because of their smoothed underlying topography all models are not capable to generate realistic wind speeds at exposed mountain ranges where all model versions underestimate wind velocities. The largest differences arise in parts of Germany where observed wind velocities take local maxima, e.g. the Brocken, Saxony's Erzgebirge, the southern part of the Black Forest and some parts of the German Alps. Here the models underestimate wind velocities by $0.5 \mathrm{~m} / \mathrm{s}$ to $2.0 \mathrm{~m} / \mathrm{s}$, even up to $2.5 \mathrm{~m} / \mathrm{s}$ at isolated grid points. Slight underestimation occurs at northern Germany's coastal region as well, but not in the coastal region of the Baltic Sea. On the other hand both REMO versions overestimate wind velocities for some parts of southern Germany by magnitudes of $1 \mathrm{~m} / \mathrm{s}$ to $1.5 \mathrm{~m} / \mathrm{s}$ if compared to observed data. The areas of overand underestimation are almost the same for all models because all models are using the same smooth topography and boundary layer parametrizations. However, for most parts of Germany the discrepancy between modeled and observed data lies within a narrow range of $\pm 0.5 \mathrm{~m} / \mathrm{s}$ and the area mean is well represented by all models. Thus, it can be concluded, that all model versions succeed in modelling realistic spatial distributions and magnitude of annual wind velocity.

Fig. 8 demonstrates that all models reproduce even the area averaged annual cycle of wind velocities quite 


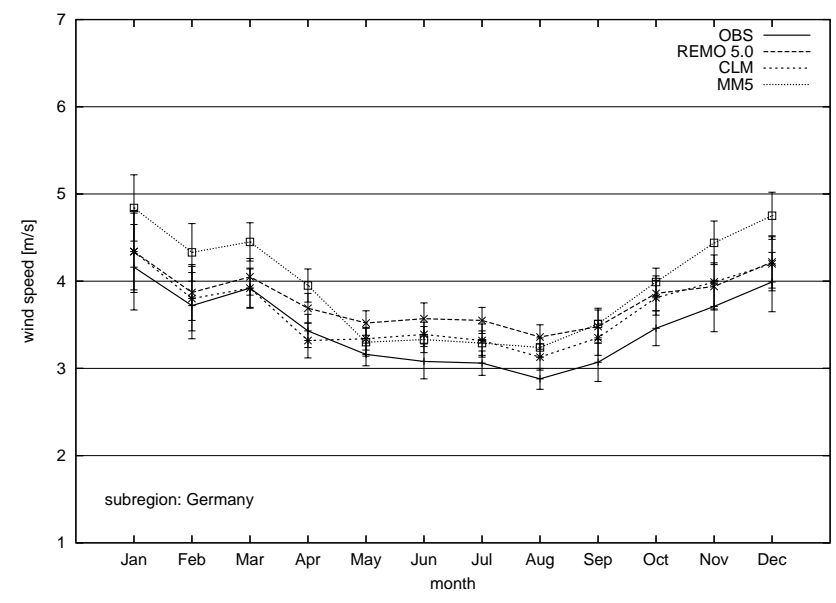

Figure 8: Mean annual cycle of wind velocities for Germany, solid is DWD reference data (OBS), dashed is REMO 5.0 (REMO 5.0), dotted is CLM (CLM) and fine dotted is MM5 (MM5). Annual means are $3.86 \mathrm{~m} / \mathrm{s}$ for REMO 5.1 (not shown), $3.79 \mathrm{~m} / \mathrm{s}$ for REMO 5.0, $3.66 \mathrm{~m} / \mathrm{s}$ for CLM, $3.95 \mathrm{~m} / \mathrm{s}$ for MM5, and $3.47 \mathrm{~m} / \mathrm{s}$ for DWD reference data set. Mean values have been calculated using $7 \times 7$ grid points. Vertical bars indicate $95 \%$ confidence level (Student's-t).

well, with a maximum difference between model and observations of $\approx 0.5 \mathrm{~m} / \mathrm{s}$ in August. The modeled velocities have a systematic positive bias compared to observations. This may be due to the fact, that wind measurements tend to slightly lower velocities when compared to real wind velocities at a given location, e.g. August is (at least in Germany) the month with lowest wind velocities. Another reason for this deviation may be the somewhat inappropriate formulation of surface roughness in all model versions. Thus, a constant offset of roughly $0.2-0.4 \mathrm{~m} / \mathrm{s}$ can be determined. The differences in annual means for the evaluation period 1979-1993 are $0.32 \mathrm{~m} / \mathrm{s}$ (REMO 5.0 - DWD), $0.39 \mathrm{~m} / \mathrm{s}$ (REMO 5.1 - DWD), 0.48 m/s (MM5 - DWD) and 0.19 $\mathrm{m} / \mathrm{s}(\mathrm{CLM}-\mathrm{DWD})$ respectively.

In Fig. 9 two mean annual cycles during the evaluation period 1979-1993 for two smaller subregions are shown. These subregions are located around $\mathrm{Mu}-$ nich (left), in the foothills of the Alps with a rather pronounced topography, and Schleswig (right) in the northern coastal region of Germany representing flat topography. The size of these subregions is $7 \times 7$ grid points, which corresponds to $\approx 125 \mathrm{~km}^{2}$. At the location Munich a discrepancy of up to $0.6 \mathrm{~m} / \mathrm{s}$ is obvious throughout the year, except for the MM5 with a somewhat larger deviation from the reference data set. Again, the largest offset occurs in August. It is not possible to decide whether the climate models overestimate wind velocities at this location because of a somewhat too smooth surface roughness or a less structured underlying topography, or if the 'observed' data underestimates the winds in this area, though IDW is an exact algorithm.
At the location Schleswig a mean discrepancy of only $0.2 \mathrm{~m} / \mathrm{s}$ occurs. This may be due to the rather unstructured topography in this coastal region. Furthermore the annual mean here is $\approx 1.5 \mathrm{~m} / \mathrm{s}$ higher than that of $\mathrm{Mu}$ nich. As mentioned above, measurements tend to represent higher wind velocities better than weak winds. This feature is also obvious in Fig. 7, where negative differences of modeled versus observed data are present in northern Germany, whereas positive differences occur in large parts of southern Germany.

It can be concluded, that the modeled wind data represent the conditions derived by DWD in the evaluation period of 1979-1993 to a large extent. Although some deviations between modeled and observed data do still exist, these deviations are inevitable for a temporal and spatial highly variable parameter such as wind velocity. Furthermore, the temporal and spatial deviations are within a narrow range, so that all models' abilities to capture all mechanisms relevant for wind velocities are unquestionable.

In Fig. 10 projections of mean changes in wind velocity according to the outcomings of several regional climate models are shown. These projections are averaged values for the period 2070 to 2099 compared to the average of the 1960 to 1989 period. The models used for these projections are REMO 5.0 (left column, without parametrization of annual vegetation cycle), REMO 5.1 (middle column, including parametrization of vegetation cycle) and the MM5 (right column). For a brief description of these models see section 3. Shown are the mean annual values (top row) and monthly averages during February representing typical winter conditions (middle row) and monthly averages during May representing summer conditions, respectively (bottom row). At least for continental Europe and the British Isles no significant change in annual means is projected by any model. On the other hand a pronounced increase in wind speed of up to $0.5 \mathrm{~m} / \mathrm{s}$ is projected by all models for the northern part of the Baltic Sea. REMO 5.0 and MM5 extend this area further west into the North Sea than REMO 5.1 does. Keep in mind, that wind direction is not a parameter in these investigations. Over large parts of the Mediterranean, especially over the Gulf of Lion in the lee of the Pyrenees negative anomalies occur. This pattern is projected by all models used.

An example for projections of changes in wind velocity during winter is given in the middle row of Fig. 10. Here, mean projected February conditions during the time period 2070-2099 are plotted. Obvious is a strong increase of wind velocity in the northern parts of the Baltic Sea of more than $2.0 \mathrm{~m} / \mathrm{s}$. Minor increases $(\approx 0.7 \mathrm{~m} / \mathrm{s})$ are projected by all models for large parts of the North Sea and REMO 5.1 even projects changes of roughly $1.0 \mathrm{~m} / \mathrm{s}$ for the English Channel. These projected changes imply higher mean wind velocities dur- 

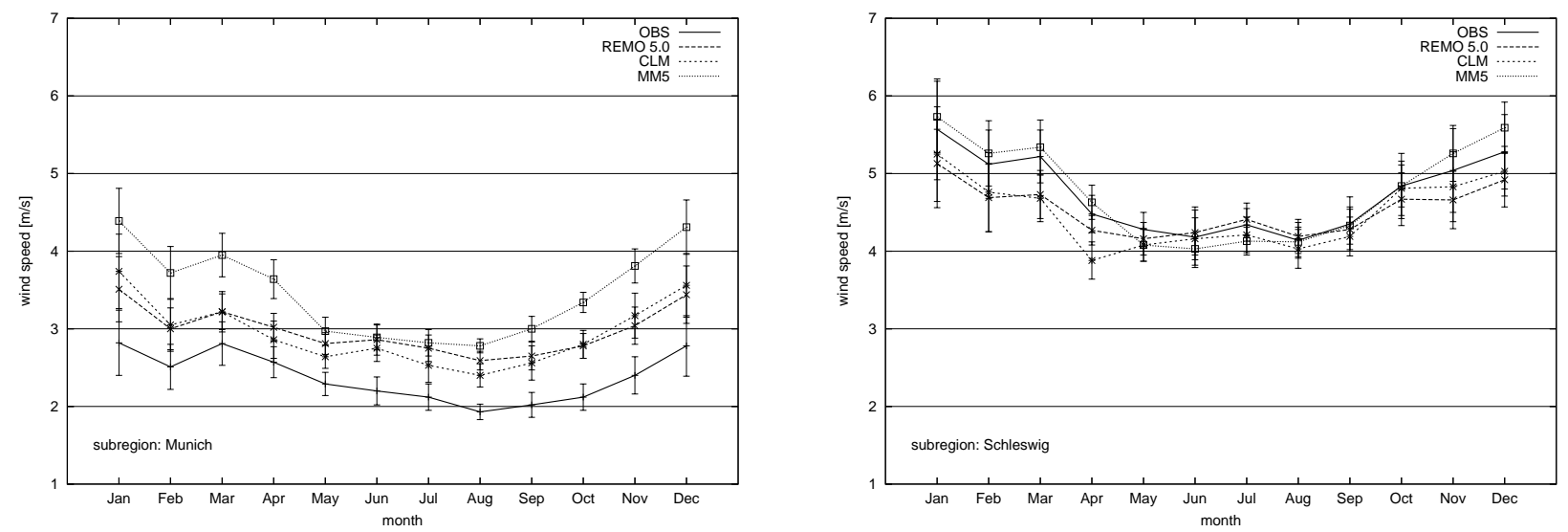

Figure 9: Similar to Fig. 8, but for subregions; left: Munich, right: Schleswig. Annual means for location Munich: $3.07 \mathrm{~m} / \mathrm{s}$ for REMO 5.1 (not shown), $2.97 \mathrm{~m} / \mathrm{s}$ for REMO 5.0, $2.94 \mathrm{~m} / \mathrm{s}$ for CLM, $3.47 \mathrm{~m} / \mathrm{s}$ for MM5, and $2.38 \mathrm{~m} / \mathrm{s}$ for DWD reference data. For location Schleswig the annual means are: $4.58 \mathrm{~m} / \mathrm{s}$ for REMO 5.1 (not shown), $4.53 \mathrm{~m} / \mathrm{s}$ for REMO 5.0, $4.49 \mathrm{~m} / \mathrm{s}$ for CLM, $4.78 \mathrm{~m} / \mathrm{s}$ for MM5 and $4.74 \mathrm{~m} / \mathrm{s}$ for DWD reference data.
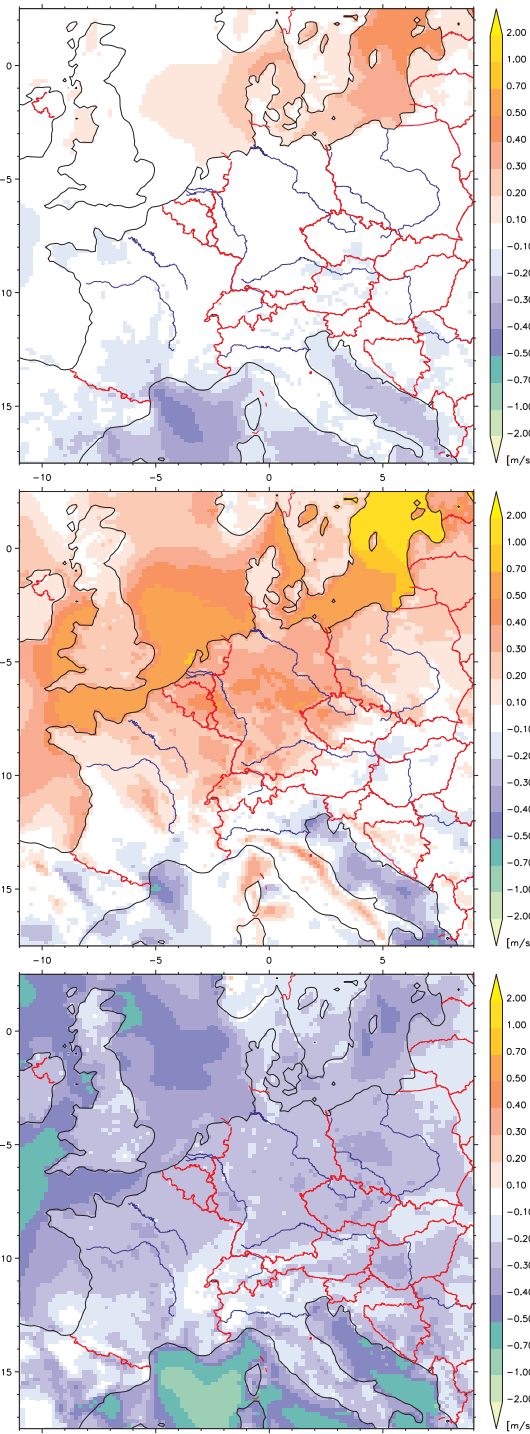
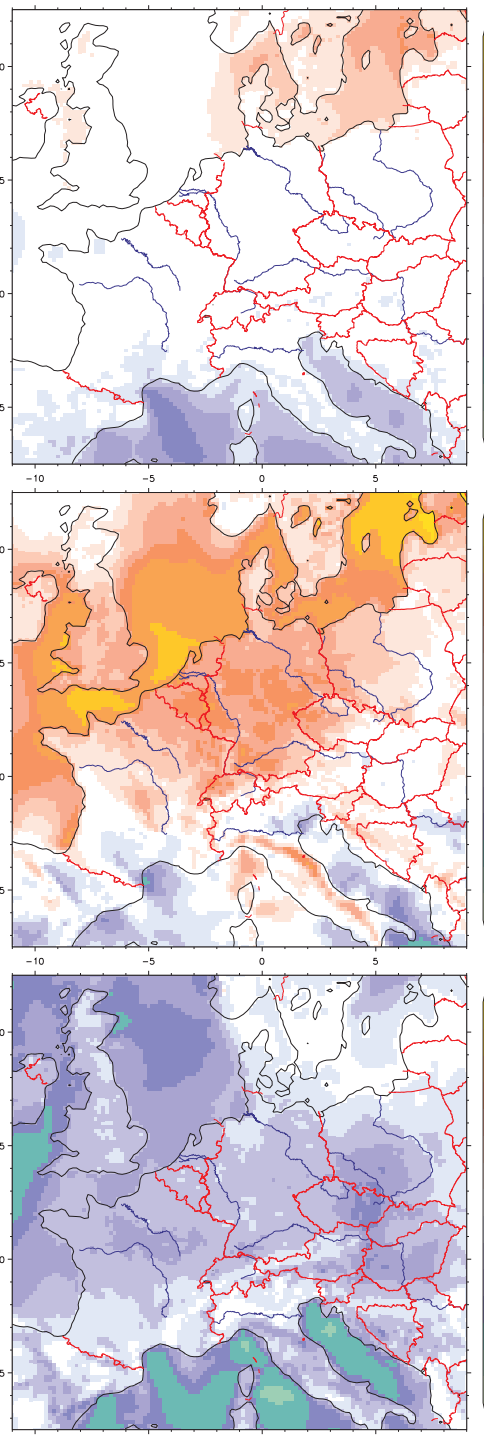
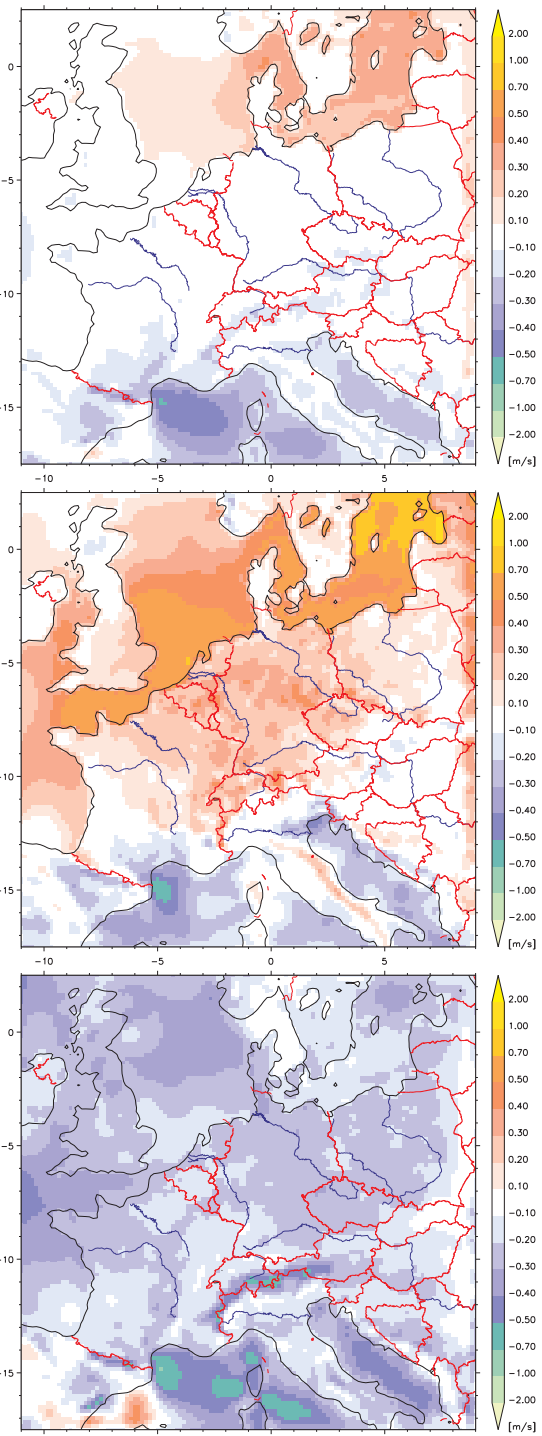

Figure 10: Projections of changes in wind velocity for the time period 2070-2099 compared to present day climate, i.e. the 1960-1989 averages. First column is REMO 5.0, second column is REMO 5.1 and third column is MM5. First row average annual values, second row average February values and third row average May values. 
ing future winters, which might lead to severe flooding events at least along northern Europes coastline if extreme storms are altered by this magnitude. All models project an increase of roughly $0.5 \mathrm{~m} / \mathrm{s}$ for Germany, thus leading to winter wind velocities of 4.5 to $5.0 \mathrm{~m} / \mathrm{s}$, see Fig. 8.

The lower panel of Fig. 10 shows averaged wind speed projections for May 2070-2099 compared to present day climate conditions (1960-1989), representing typical summer conditions. Most parts of the model domain will experience a decrease in wind velocity during a typical summer period according to the outcomings of all models applied. This decrease is most pronounced over the Mediterranean, with a decline of up to $-2.0 \mathrm{~m} / \mathrm{s}$. According to both REMO versions wind velocity will be reduced by $-0.5 \mathrm{~m} / \mathrm{s}$ over open waters, $-0.3 \mathrm{~m} / \mathrm{s}$ (MM5) respectively. For Germany a reduction of $\approx-0.4 \mathrm{~m} / \mathrm{s}$ is projected by all models.

This implies that the average annual cycle of wind velocities will be in general more pronounced because its range will be expanded to average values from 2.5 $\mathrm{m} / \mathrm{s}$ (summer) to $5.0 \mathrm{~m} / \mathrm{s}$ (winter), see again Fig. 8 . Again, this projection for Germany is almost identical for all models and may be most pronounced in the outcomings of REMO 5.0 (left).

\section{Conclusions}

A high resolution reference data set of German wind velocities for the period 1951 to 2001 has been provided.

This data set serves furtheron as an evaluation set for regional climate models during their evaluation period 1979-1993, wherein only minor deviations between modelled and observed data can be detected $( \pm 1.0 \mathrm{~m} / \mathrm{s})$. Only at isolated grid points in topographically strongly structured terrain all models underestimate wind velocity due to their underlying too smooth topography (Fig. 7).

Projections of annual wind velocity for the time period 2070-2099 have been carried out, using three regional climate models. These projections have been compared to conditions in the 1960-1989 period and, regarding annual averages, suggest a nearly unchanged wind regime over continental Europe but an increase of $0.5 \mathrm{~m} / \mathrm{s}$ over the Baltic Sea, see Fig. 10. During winter this increase becomes more pronounced $(\approx 2.0 \mathrm{~m} / \mathrm{s})$, especially over the Baltic- and North Sea. This increase is accompanied by a decrease of wind velocities over the Mediterranean.

According to the model outputs summer wind velocities will decrease by $0.5 \mathrm{~m} / \mathrm{s}$ throughout the whole model domain.

\section{Acknowledgements}

The present study has been carried out within the research project QUIRCS which was funded by the Ger- man Climate Research Program DEKLIM. The authors wish to thank all involved persons for their constant support and supply of data, model results and figures. We are also grateful to the reviewers for their constructive comments and helpful suggestions on the manuscript.

\section{References}

Allen, M.R., P.A. Stott, J.F.B. Mitchell, R. SCHNUR, T.L. DELWORTH, 2000: Quantifying the uncertainty in forecasts of anthropogenic climate change. - Nature 407, 617-620.

BenEsCH, W., G. Duensing, G. JURKSCH, R. ZÖLLNER, 1978: Die Windverhältnisse in der Bundesrepublik Deutschland im Hinblick auf die Nutzung der Windkraft. Deutscher Wetterdienst. - Berichte des Deutschen Wetterdienstes Nr. 147, Offenbach am Main, 144 pp.

Dittmann, E., G. Müller-Westermeier, A. Kreis, P. Fuchs, S. Szalai, Z. Bihari, A. Bussay, T. SZEnTIMREY, C. SZINELL, 1999: Spatial Interpolation of Climatological Parameters. - Deutscher Wetterdienst, Arbeitsergebnisse Nr. 57, Offenbach am Main, 46 pp.

Doms, G., U. Schaettler, 1999: The Nonhydrostatic Limited-Area Model LM (Lokal Modell) of DWD. Part 1: Scientific Documentation. - Available from www.cosmomodel.org.

DUDHIA, J., 1993: A nonhydrostatic version of the Penn State - NCAR mesoscale model: Validation tests and simulation of an atlantic cyclone and cold front. - Mon. Wea. Rev. 121, 1493-1513.

ECMWF Reports, 1997-1999: ERA-15 Project Report Series. - Available from www.ecmwf.int/publications/library/ do/references/list/191/.

Forest, C.E., P.H. Stone, A.P. Sokolov, M.R. Allen, M.D. Webster, 2002: Quantifying uncertainties in climate system properties with the use of recent climate observations. - Science 295, 113-117.

FORKEL, R., R. KNOCHE, accepted: Regional climate change and its impacts on photooxydent concentrations in southern Germany: Simulations with a coupled regional climate chemistry model. - J. Geophys. Res.

Goodin, W.R., G.J. MCrAe, J.H. Seinfeld, 1979: A Comparison of Interpolation Methods for Sparse Data: Application to Wind and Concentration Fields. - J. Appl. Meteor. 18, 761-771.

Grell, G.A., J. Dudhia, D.R. Stauffer, 1993: A Description of the Fifth-Generation Penn State/NCAR Mesoscale Model (MM5). - National Center for Atmospheric Research, NCAR Technical Note TN-398+STR, Boulder, CO., 122 pp.

Grell, G.A., S. EMEIS, W.R. StockWell, T. SChOenEMEYER, R. FORKEL, J. Michalakes, R. KNOCHE, W. SEIDL, 2000a: Application of a multiscale, coupled MM5/chemistry model to the complex terrain of the VOTALP valley campaign. - Atmos. Environ. 34, 14351453

Grell, G.A., L. Schade, R. Knoche, A. Pfeiffer, J. EGGER, 2000b: Nonhydrostatic climate simulations over complex terrain. - J. Geophys. Res. 105, D4, 29595-29608. 
HartKamp, A.D., K. De Beurs, A. Stein, J.W. White, 1999: Interpolation Techniques for Climate Variables. CIMMYT, NRG-GIS Series 99-01, Mexico, 34 pp.

JАCOB, D., 2001: A note to the simulation of the annual and inter-annual variability of the water budget over the Baltic Sea drainage basin. - Meteor. Atmos. Phys. 77, 61-73.

JACOB, D., R. Podzun, 1997: Sensitivity studies with the regional climate model REMO. - Meteor. Atmos. Phys. 63, 119-129.

MAJEWSKI, D., 1991: The Europa-Modell of the Deutscher Wetterdienst. - ECMWF Seminar on Numerical Methods in Atmospheric Models, 2, 147-191.

Mathur, R., L.K. Peters, 1990: Adjustment of wind fields for application in air pollution modeling. - Atmos. Environ. 24A, 1095-1106.

Michaelsen, J., 1987: Cross-Validation in Statistical Climate Forecast Models. - J. Climate Appl. Meteor. 26, $1589-1600$.

Murphy, J.M., D.M. Sexton, D.N. Barnett, G.S. Jones, M.J. Webb, M. Collins, D.A. Stainforth, 2004: Quantification of modelling uncertainties in a large ensemble of general circulation model predictions. - Nature 430, 768-772.

ROECKNER, E., K. ARPE, L. BengtSSON, M. Christoph, M. Claussen, L. DÜMEnil, M. EsCh, M. Giorgetta, U. SchleSE, U. SchulzWEIDA, 1996: The atmospheric general circulation model ECHAM-4: Model description and simulation of the present day climate. Max Plack Institut für Meteorologie, MPI Report Nr. 218, Hamburg.

Ross, D.G., I.N. Smith, P.C. Manins, D.G. Fox, 1988: Diagnostic Wind Field Modeling for Complex Terrain: Model Developement and Testing. - J. Appl. Meteor. 27, 785-796.

SCHUlZE, O., 1993: Der Wind auf dem Brocken, eine statistische Betrachtung über den windigsten Standort in Deutschland. Internal publication, German Met. Service. Available from the library of the German Meteorological Service.

Sherman, C.A., 1978: A Mass-Consistent Model for Wind Fields over Complex Terrain. - J. Appl. Meteor. 17, 312319.

STEPHANS, J.J., J.M. STITT, 1970: Optimum influence radii for interpolation with the method of succesive corrections. - Monthly Wea. Rev. 98, 680-687.

StOne, M., 1974: Cross-validatory Choice and Assessments of Statistical Predictors. - J. Roy. Stat. Soc. B36, 111-147.

Weisse, R., H. Von Storch, F. Feser, 2005: Northeast Atlantic and North Sea storminess as simulated by a regional climate model 1958-2001 and comparison with observations. - J. Climate 18, 465-479. 